\title{
Comparative anatomical study of standard percutaneous and modified medialised percutaneous Bunnell type repair for artificial Achilles tendon rupture: positive effect of medialisation of the stitches with lower risk of sural nerve injury
}

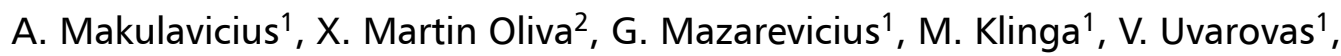 \\ N. Porvaneckas ${ }^{1}$, M. Monzó Planella², T. Mazurek ${ }^{3}$ \\ ${ }^{1}$ Republican Vilnius University Hospital, Vilnius University, Medical Faculty, \\ Centre of Orthopaedics and Traumatology, Lithuania \\ ${ }^{2}$ Department of Embryology and Human Anatomy, Medical Faculty, University of Barcelona, Spain \\ ${ }^{3}$ Orthopaedics Department, Medical University of Gdansk, Poland
}

[Received: 16 April 2015; Accepted: 23 June 2015]

Background: Less invasive percutaneous acute Achilles tendon rupture (AATR) repair techniques gain popularity because of lower risk of surgical wound complications. But these approaches have an increased risk of sural nerve iatrogenic injury as this sensory nerve is usually not visualised during minimally invasive operative procedures. We compared standard percutaneous Bunnell type and our proposed modified-medialised percutaneous technique in a cadaver study to evaluate potential advantages.

Materials and methods: Ten pairs of fresh frozen specimens were divided into two groups for comparative anatomical study. Tenotomies of Achilles tendons were made and wounds sutured. Ten standard and 10 modified-medialised repairs were applied for artificially performed ruptures. All sutured tendons were dissected meticulously. We carefully looked at repaired Achilles tendon end-to-end contact and adaptation, distance from Achilles insertion in calcaneal tubercle to place where sural nerve crosses lateral border of the Achilles tendon and possible sural nerve and vein entrapment. Groups were compared using Fisher's exact and Student-T tests. Results: All ends of sharply dissected tendons in both groups were in sufficient contact. No measurable diastasis between tendon ends was found in all cases. No entrapment of sural nerve or vein was found in modified percutaneous Bunnell suture technique group, whereas 7 of 10 sural nerves and 9 small saphenous veins were entrapped when using standard percutaneous Bunnell type technique. Average distance from Achilles tendon insertion in tuber calcanei to sural nerve crossing the lateral border of Achilles was $93 \mathrm{~mm}$.

Conclusions: Medialisation of percutaneous suture in AATR repair shows clear advantages compared to standard non medialised technique ensuring a possible lower incidence of sural nerve entrapment injury. Our modified percutaneous Bunnell type technique allows sufficient adaptation of ruptured Achilles tendon. (Folia Morphol 2016; 74, 1: 53-59)

Key words: Achilles repair, percutaneous, medialisation

Address for correspondence: Dr A. Makulavicius, Republican Vilnius University Hospital, Vilnius University, Medical Faculty, Centre of Orthopaedics and Traumatology, Lithuania, e-mail: makulaviciusa@gmail.com 


\section{INTRODUCTION}

The aim of the treatment of an acute Achilles tendon rupture (AATR) is restoration of integrity of the tendon with proper length ensuring muscle strength. Conservative treatment is rarely used because it has a high chance of tendon lengthening with loss of muscle power and increased rate of Achilles tendon re-ruptures $[2,7,13,19,32]$. Open surgical treatment of an AATR can effectively reduce the risk of re-ruptures, but it could have more surgical wound complications as is shown by many publications and some recent meta-analysis $[2,7,8,10,13,19,32]$.

Recent findings show that percutaneous and minimally-invasive techniques are more cost effective than open techniques [4]. Variety of minimally-invasive techniques are being used for AATR repair with an aim to avoid severe surgical wound complications [5-9, $12,14-17,20,23-25,27-29,31,34,35,38,40,41]$, but most blind percutaneous techniques place the sural nerve at high risk of iatrogenic injury $[14,40,41]$. Standard sural nerve anatomy is well known with some possible variations [36, 38, 39], but is not usually respected by percutaneous repair techniques to avoid its injury.

The aim of our study was to introduce a completely new technique modification and perform a comparative cadaver anatomical study to prove advantages in modified percutaneous Bunnell type technique with suture medialisation ensuring lower risk of iatrogenic injury with possible nerve puncture or entrapment.

\section{MATERIALS AND METHODS}

We performed cadaver study in the Department of Embryology and Human Anatomy of Barcelona University, Spain.

Ten pairs of fresh frozen leg specimens were divided into two groups for comparative anatomical study. Tenotomies of all Achilles tendons were established through $2-3 \mathrm{~cm}$ long transverse skin incisions, $5 \mathrm{~cm}$ above the calcaneal tubercle, as it is the most common area where tendon ruptures as shown by clinical findings, literature and model by Mazur et al. [26]. We used standard percutaneous Bunnell type stitching technique in first group (Fig. 1) and newly introduced modified medialised Bunnell type percutaneous stitching technique in the second group, when the sutures were placed medially to calf midline in ruptured Achilles tendon, with an aim to stay away from the sural nerve (Fig. 2).

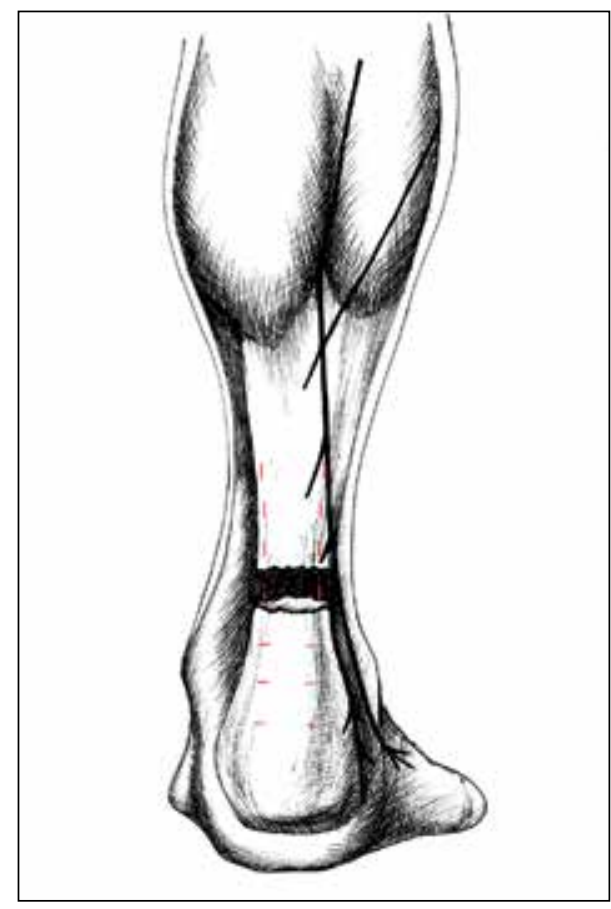

Figure 1. Standard technique.

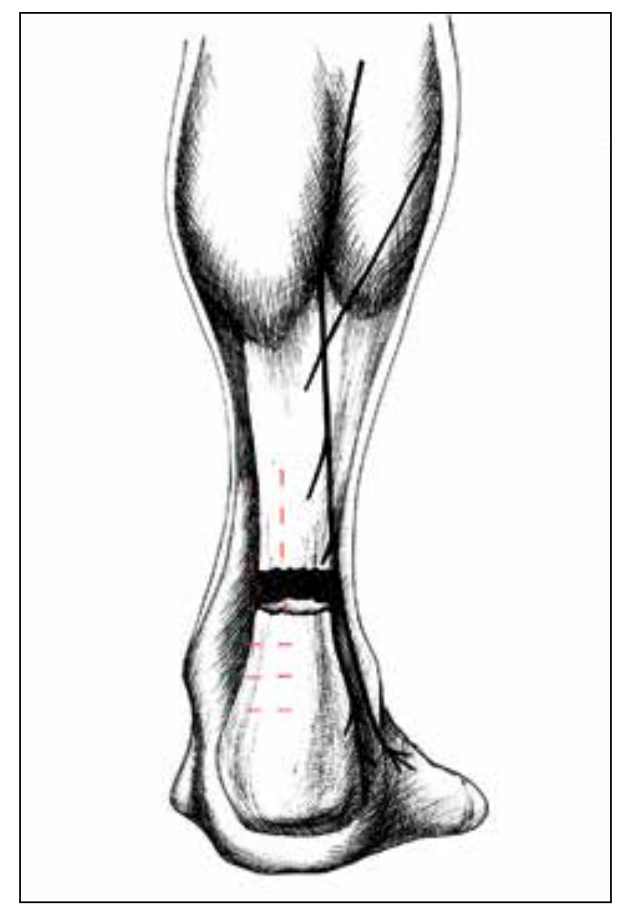

Figure 2. Modified medialized technique.

We evaluated contact and adaptation of Achilles tendon ends, distance from Achilles insertion in calcaneal tubercle to place where sural nerve crosses lateral border of the Achilles tendon and sural nerve 
Table 1. Results of sural nerve entrapment

\begin{tabular}{|c|c|c|c|c|c|c|}
\hline Spec. No. & Medialisation & Damage to nerve & Suture count ${ }^{*}$ & Damage to vein & $\begin{array}{l}\text { Calcaneal-Achilles } \\
\text { lateral border** }\end{array}$ & Suture-nerve ${ }^{* * *}$ \\
\hline 1 & Yes & No & 0 & No & 8.40 & 1.7 \\
\hline 2 & Yes & No & 0 & No & 7.60 & 1.1 \\
\hline 3 & Yes & No & 0 & No & 9.88 & 0.5 \\
\hline 4 & Yes & No & 0 & No & 9.54 & 1.1 \\
\hline 5 & Yes & No & 0 & No & 9.56 & 0.9 \\
\hline 6 & Yes & No & 0 & No & 10.50 & 1.8 \\
\hline 7 & Yes & No & 0 & No & 8.11 & 1.5 \\
\hline 8 & Yes & No & 0 & No & 9.91 & 0.5 \\
\hline 9 & Yes & No & 0 & No & 7.95 & 1.3 \\
\hline 10 & Yes & No & 0 & No & 8.56 & 1.1 \\
\hline 11 & No & Yes & 1 & Yes & 10.70 & 0 \\
\hline 12 & No & Yes & 1 & Yes & 11.12 & 0 \\
\hline 13 & No & Yes & 1 & Yes & 9.50 & 0 \\
\hline 14 & No & Yes & 2 & Yes & 8.70 & 0 \\
\hline 15 & No & Yes & 1 & Yes & 9.20 & 0 \\
\hline 16 & No & Yes & 1 & Yes & 8.70 & 0 \\
\hline 17 & No & Yes & 1 & Yes & 9.43 & 0 \\
\hline 18 & No & No & 0 & No & 10.14 & 0.4 \\
\hline 19 & No & No & 0 & Yes & 7.11 & 0.6 \\
\hline 20 & No & No & 0 & Yes & 11.42 & 0.3 \\
\hline
\end{tabular}

${ }^{*}$ Count of sutures entrapping the sural nerve; ${ }^{*}$ Distance from Achilles insertion in calcaneal tubercle to place where sural nerve crosses lateral border of the Achilles tendon; ***Distance from most lateral part of suture to sural nerve

and vein entrapment. Distances were measured in millimetres using standard ruler.

Statistical analysis was done in MS EXCEL and SPSS. Fisher's exact test, Student independent T tests were used to compare groups. $\mathrm{P}<0.05$ meant statistical significance.

\section{RESULTS}

All ends of Achilles tendons were in full contact in all cases of both groups. We did not find any diastasis. This supports our idea of getting adequate end-to-end contact and adaptation using percutaneous technique. In real clinical situation fascia and paratenon provide additional supporting forces for adaptation.

No entrapment of sural nerve or small saphenous vein was found in a group of modified medialised percutaneous suture technique. Closest proximal stitches were placed 5-18 mm (mean $11.5 \pm 4.2 \mathrm{~mm}$; Table 1) from sural nerve or small saphenous vein in this group. However, in standard percutaneous technique group without medialisation -7 sural nerves and small saphenous veins entrapments were detected. In the same standard repair group we found 2 cases with additional entrapment of small saphenous vein without sural nerve entrapment. Only in 3 cases no damage to neurovascular structures was found, but closest proximal stitches were placed 0-6 $\mathrm{mm}$ (mean $1.3 \pm$ $\pm 2.1 \mathrm{~mm}$ ) from the nerve and small saphenous vein (Figs. 3-6).

Power of Fisher's exact test was 0.95. Incidence of sural nerve damage when using modified technique was significantly lower ( $p<0.001)$.

Mean distance from insertion of Achilles tendon into calcaneal tubercle to place where sural nerve crosses lateral border of Achilles tendon was 7.11$-11.12 \mathrm{~cm}$ (mean $9.30 \pm 1.14 \mathrm{~cm}$ ). This was the most risky zone for sural nerve entrapment. Our data is similar to previously described by various authors.

\section{DISCUSSION}

Different authors describe different sural nerve damage ratio with percutaneous techniques ranging from $4.5 \%$ to $18 \%[1,22,33,37,42]$. There are diffe- 


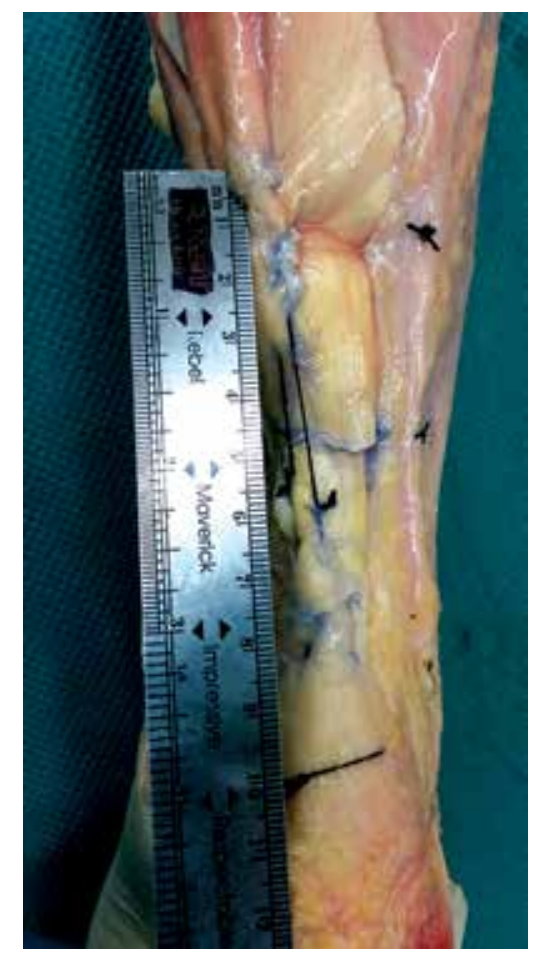

Figure 3. Actual modified technique.

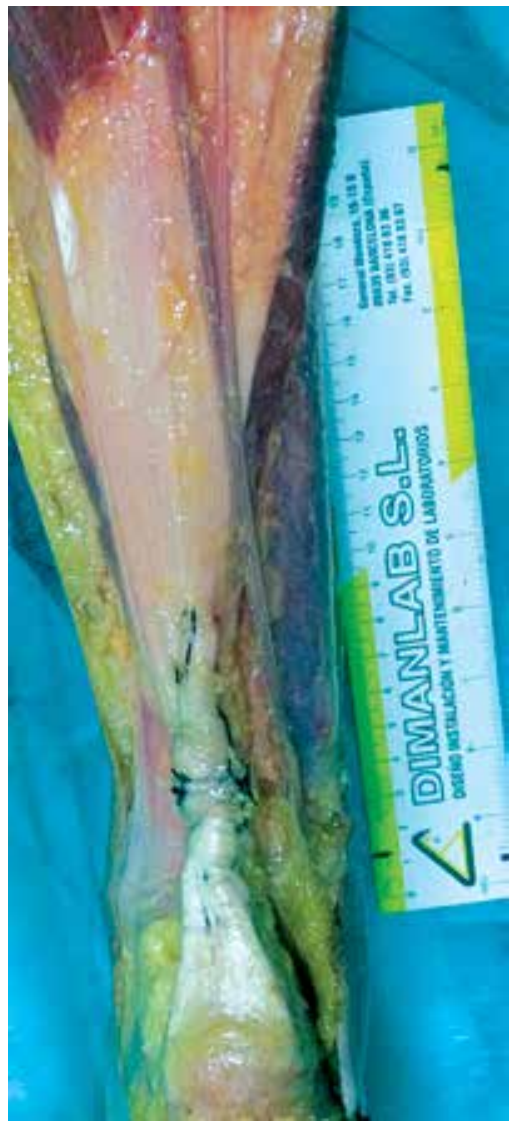

Figure 4. Specimen with standard technique.

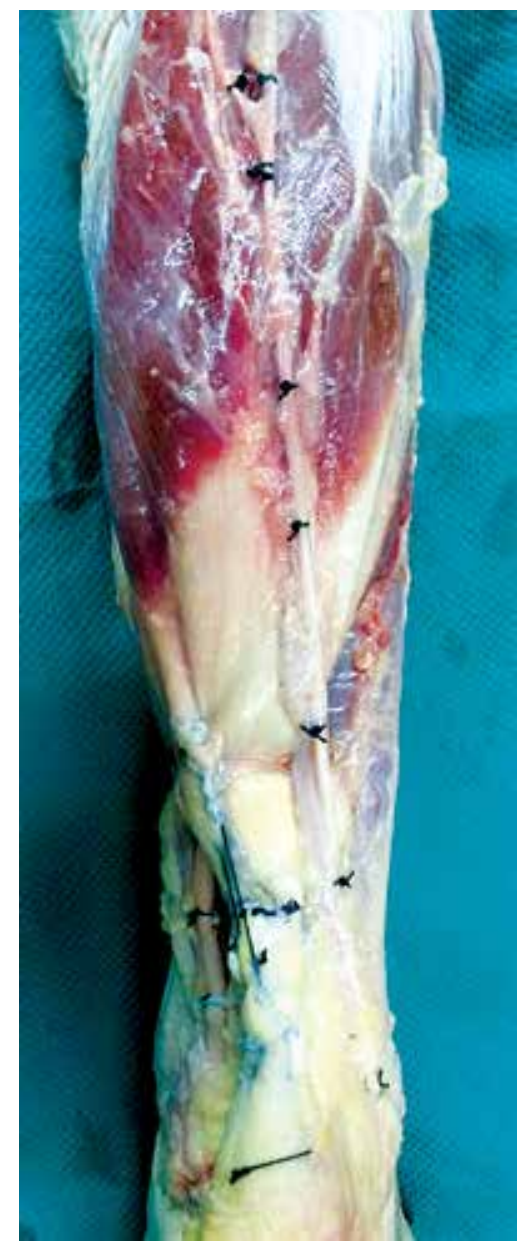

Figure 5. Sural nerve and vein are marked.

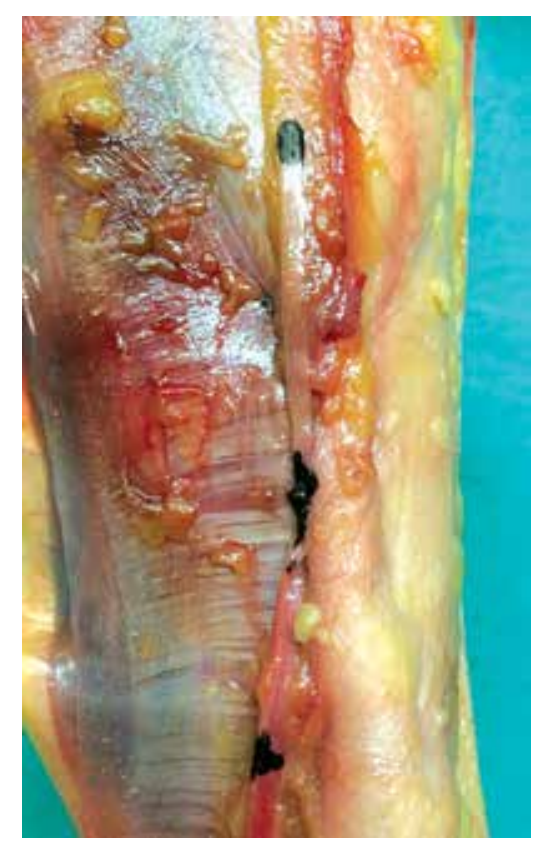

Figure 6. Zoomed view of entrapped nerve. 
rent reasons, with technique being one of the most important factors. This difference can be partially explained, because sural nerve has a varying anatomy.

This nerve is a major cutaneous nerve of the lower limb that courses through the posterolateral leg, staying close to the small saphenous vein and supplying the lateral margin of the hindfoot and midfoot, and the ankle joint. The nerve usually consists of 4 named parts: the medial sural cutaneous nerve, the lateral sural cutaneous nerve, the peroneal communicating branch, and the sural nerve [33].

However, Huelke [13] found, that only $80.5 \%$ of population (550 different limbs) had normal sural nerve anatomy, when the sural nerve terminates as branches to the heel, with the lateral sural cutaneous nerve passing onto the foot, others $19.5 \%$ are divided into two types - when the medial sural cutaneous nerve passes onto the foot as the lateral dorsal cutaneous nerve $(19.1 \%)$, or when the medial sural cutaneous nerve terminates as cutaneous branches to the heel with the lateral sural cutaneous nerve passing onto the foot. There is no typical sural nerve in these two types. The peroneal communicating nerve has a variable origin, but the same type of origin occurred on both sides in only 58 of 99 cadavers (58.6\%).

Important topic of research is the relation of the sural nerve to the Achilles tendon, especially where it crosses the lateral border of Achilles tendon. This part of the nerve is at risk during percutaneous repair of Achilles tendon. Porter et al. [34] found that the sural nerve was found lateral to the Achilles tendon insertion point over a range of $14.3 \mathrm{~mm}$. Webb et al. [38] found and Flavin et al. [7] reproduced that the sural nerve passes between the two heads of the gastrocnemius muscle, piercing the deep fascia and travels laterally across the gastro-soleus complex to cross the lateral border of the Achilles tendon approximately 98 $\mathrm{mm}$ proximal to the tendon insertion. The sural nerve passes approximately $18 \mathrm{~mm}$ posterior to the lateral malleolus to innervate the lateral aspect of the foot. Citak et al. [6] describes the sural nerve crossing the Achilles tendon at $11 \mathrm{~cm}(8.7-12.4 \mathrm{~cm})$ proximal to the tuber calcanei.

Ma and Griffith [23] described mini-invasive percutaneous Achilles tendon repair. Suture crosses the tendon through 6 medial and lateral short skin incisions and is tied under the skin. Authors did not describe any sural nerve damage or irritation of it. However, there are two problems with this approach. First, there is a risk of sural nerve injury and, second, since there is no open incision at the rupture site, the quality of the repair cannot be confirmed visually as the tendon ends are brought into apposition in a closed manner. However, Rowley and Scotland [35] reported injury to the sural nerve in one of ten patients using the same technique.

Majewski et al. [25] reported a reduction in sural nerve injuries by exposing the nerve in conjunction with the Ma and Griffith [23] percutaneous technique from $18 \%$ to $0 \%$. To the best of our knowledge there is no reproducible technique for identifying the sural nerve clinically without surgical exposure in acute Achilles tendon ruptures.

Klein et al. [19] have described 5 injuries of the sural nerve in 38 operated patients and afterwards modified the technique described above. They used longer (about $2 \mathrm{~cm}$ ) bilateral skin incisions to visualize sural nerve and retract it. Various other studies have been performed, yet none strongly suggested medialising the suture to avoid sural nerve damage.

There are several other solutions offered to avoid sural nerve damage, including open dissection of sural nerve in the most risky zone. But these approaches diminish cosmetic advantages of pure percutaneous techniques, which could be important for some patients, especially young women.

Hamilton et al. [10] showed medial head of gastrocnemius being larger and more important. We absolutely agree with this opinion and employ the stronger and thicker medial part of Achilles tendon for modified medialised percutaneous Bunnell type repair ensuring sufficient primary tendon repair strength.

Hockenbury and Johns [12] in their cadaver study found that the sural nerve had been trapped by the proximal suture in three out of 5 specimens repaired using their technique. Our method uses medialised skin incisions and suture placements with an aim to lower incidence of this problem.

We should also note some weaknesses of our study. We had incomplete lower leg specimen just below knee joint with loose gastrocnemius muscle and relaxed muscle-tendon junction. This is different from real situation of full length leg specimen where muscle is tight proximally. We also did not know the gender and real height of the cadaver and this could influence the results. Higher patients have longer legs, meaning sural nerve should cross lateral border of Achilles higher. Age was also not noted, yet it can influence sural nerve anatomy and histology as shown by Mizia et al. [30]. 
We also did not measure sural nerve position to Achilles tendon in sagittal plane. Authors describe a varying sural nerve position in all planes, not only frontal plane. However, since we offer modified medialisation technique of the suture, we believe that the sural nerve sagittal plane is less important.

Despite all shortcomings of our anatomical study, it still proved that medialising suture in AATR decreases the risk of sural nerve damage. One can expect a statistically significant lower incidence of sural nerve damage when applying modified medialised percutaneous Achilles tendon repair technique.

\section{CONCLUSIONS}

Medialisation of percutaneous suture show clear advantages compared with standard percutaneous technique ensuring a lower incidence of sural nerve and small saphenous vein entrapment injury. This technique allows sufficient adaptation of injured Achilles tendon ends.

\section{REFERENCES}

1. Aktas S, Kocaoglu B (2009) Open versus minimal repair with Achillon device. Foot Ankle Int, 30: 391-397.

2. Bhandari M, Guyatt GH, Siddiqui F, Morrow F, Busse J, Leighton RK, Sprague S, Schemitsch EH (2002) Treatment of acute Achilles tendon ruptures: a systematic overview and meta-analysis. Clin Orthop Relat Res, 400: 190-200.

3. Bruggeman NB, Turner NS, Dahm DL, Voll AE, Hoskin TL, Jacofsky DJ, Haidukewych GJ (2004) Wound complications after open Achilles tendon repair. An analysis of risk factors. Clin Orthop Relat Res, 427: 63-66.

4. Carmont MR, Heaver C, Pradhan A, Mei-Dan O, Gravare Silbernagel K (2013) Surgical repair of the ruptured Achilles tendon: the cost-effectiveness of open versus percutaneous repair. Knee Surg Sports Traumatol Arthrosc, 21: 1361-1368.

5. Ceccarelli F, Berti L, Giurati L, Romagnoli M, Giannini S (2007) Percutaneous and minimally invasive techniques of Achilles' tendon repair. Clin Orthop Rel Res, 458: 188-193.

6. Citak M, Knobloch K, Albrecht K, Krettek C, Huffner T (2007) Anatomy of the sural nerve in a computer-assisted model: implications for surgical minimally-invasive Achilles tendon repair. Br J Sports Med, 41: 456-458.

7. Flavin R, Gibney RG, O'Rourke SK (2007) A clinical test to avoid sural nerve injuries in percutaneous Achilles tendon repairs. Injury, 38: 845-847.

8. Gigante A, Moschini A, Verdenelli A, Del Torto M, Ulisse S, de Palma L (2008) Open vs percutaneous repair in the treatment of acute Achilles tendon rupture: a randomized prospective study. Knee Surg Sports Traumatol Arthroscopy, 16: 204-209.

9. Haji A, Sahai A, Symes A, Vyas JK (2004) Percutaneous versus open tendo achillis repair. Foot Ankle Int, 25: 215-218.

10. Hamilton PD, Brown M, Ferguson N, Adebibe M, Maggs J, Solan M (2009) Surgical anatomy of the proximal release of the gastrocnemius: a cadaveric study. Foot Ankle Int, 30: 1202-1206.
11. Henriquez H, Munoz R, Carcuro G, Bastias Ch (2012) Is percutaneous repair better than open repair in acute Achilles tendon rupture? Clin Orthop Relat Res, 470: 998-1003.

12. Hockenbury RT, Johns JC (1990) A biomechanical in vitro comparison of open versus percutaneous repair of tendon achilles. Foot Ankle, 11: 67-72.

13. Huelke DF (1958) The origin of the peroneal communicating nerve in adult man. Anat Rec, 132: 81-92.

14. Jiang N, Wang B, Chen A, Dong F, Yu B (2012) Operative versus nonoperative treatment for acute Achilles tendon rupture: a meta-analysis based on current evidence. Int Orthop, 36: 765-773.

15. Kakiuchi M (1995) A combined open and percutaneous technique for repair of tendo Achillis. Comparison with open repair. J Bone Joint Surg Br, 77: 60-63.

16. Kammar H, Carmont MR, Kots E, Laver L, Mann G, Nyska M, Mei-Dan O (2014) Anatomy of the sural nerve and its relation to the Achilles tendon by ultrasound examination. Orthopedics, 37: e298-e301.

17. Keating JF, Will EM (2011) Operative versus non-operative treatment of acute rupture of tendo Achillis: a prospective randomised evaluation of functional outcome. J Bone Joint Surg $B r$, 93: 1071-1078.

18. Khan RJ, Fick D, Keogh A, Crawford J, Brammar T, Parker M (2005) Treatment of acute Achilles tendon ruptures. A meta-analysis of randomized, controlled trials. J Bone Joint Surg Am, 87: 2202-2210.

19. Klein W, Lang DM, Saleh M (1991) The use of the Ma-Griffith technique for percutaneous repair of fresh ruptured tendo Achillis. Chir Organi Mov, 76: 223-228.

20. Kocher MS, Bishop J, Marshall R, Briggs KK, Hawkins RJ (2002) Operative versus nonoperative management of acute Achilles tendon rupture: expected-value decision analysis. Am J Sports Med, 30: 783-790.

21. Lawrence SJ, Botte MJ (1994) The sural nerve in the foot and ankle: an anatomic study with clinical and surgical implications. Foot Ankle Int, 15: 490-494.

22. Lim J, Dalal R, Waseem M (2001) Percutaneous vs. open repair of the ruptured Achilles tendon: a prospective randomized controlled study. Foot Ankle Int, 22: 559-568.

23. Ma GW, Griffith TG (1977) Percutaneous repair of acute closed ruptured Achilles tendon. A new technique Clin Orthop, 128: 247-255.

24. Maes R, Copin G, Averous C (2006) Is percutaneous repair of the Achilles tendon a safe technique? A study of 124 cases. Acta Orthop Belg, 72: 179-183.

25. Majewski M, Rohrbach M, Czaja S, Ochsner P (2006) Avoiding sural nerve injuries during percutaneous Achilles tendon repair. Am J Sports Med, 34: 793-798.

26. Mazur L, Młyniec A, Tomaszewski K, Walocha J, Uhl T (2014) A multiscale model of the Achilles tendon: from molecular and coarse-grain simulations to a macroscale hyperelastic model. Wulfenia, 21: 341-355.

27. McMahon SE, Smith TO, Hing CB (2011) A meta-analysis of randomised controlled trials comparing conventional to minimally invasive approaches for repair of an Achilles tendon rupture. Foot Ankle Surg, 17: 211-217.

28. Metz R, van der Heijden GJ, Verleisdonk EJ, Tamminga R, van der Werken C (2009) Recovery of calf muscle strength following acute Achilles tendon rupture treatment: a comparison between minimally invasive surgery and conservative treatment. Foot Ankle Spec, 2: 219-226. 
29. Metz R, Verleisdonk EJ, van der Heijden GJ, Clevers GJ, Hammacher ER, Verhofstad MH, van der Werken C (2008) Acute Achilles tendon rupture: minimally invasive surgery versus nonoperative treatment with immediate full weight bearing: a randomized controlled trial. Am J Sports Med, 36: 1688-1694.

30. Mizia E, Tomaszewski KA, Rutowicz B, Konopka T, Pasternak A, Walocha JA (2014) Computer-assisted assessment of the histological structure of the human sural nerve. Folia Morphol, 73: 292-297.

31. Moller M, Movin T, Granhed H, Lind K, Faxen E, Karlsson J (2001) Acute rupture of tendo Achillis. A prospective randomised study of comparison between surgical and non-surgical treatment. J Bone Joint Surg $\mathrm{Br}, 83$ : 843-848.

32. Nilsson-Helander K, Silbernagel KG, Thomeé R, Faxén E, Olsson N, Eriksson BI, Karlsson J (2010) Acute Achilles tendon rupture: a randomized, controlled study comparing surgical and nonsurgical treatments using validated outcome measures. Am J Sports Med, 38: 2186-2193.

33. Ortigüela ME, Wood MB, Cahill DR (1987) Anatomy of the sural nerve complex. J Hand Surg Am, 12: 1119-1123.

34. Porter KJ, Robati S, Karia P, Portet M, Szarko M, Amin A (2014) An anatomical and cadaveric study examining the risk of sural nerve injury in percutaneous Achilles tendon repair using the Achillon device. Foot Ankle Surg, 20: 90-93.
35. Rowley DI, Scotland TR (1982) Rupture of the Achilles tendon treated by a simple operative procedure. Injury, 14: 252-254.

36. Solomon LB, Ferris L, Tedman R, Henneberg M (2001) Surgical anatomy of the sural and superficial fibular nerves with an emphasis on the approach to the lateral malleolus. J Anat, 199 (Part 6): 717-723.

37. Wagnon R, Akayi M (2005) The Webb-Bannister percutaneous technique for acute Achilles' tendon ruptures: a functional and MRI assessment. J Foot Ankle Surg, 44: 437-444.

38. Webb J, Moorjani J, Radford M (2000) Anatomy of the sural nerve and its relation to the Achilles tendon. Foot Ankle Int, 21: 475-477.

39. Webb JM, Bannister GC (1999) Percutaneous repair of the ruptured tendo Achillis. J Bone Joint Surg Br, 81: 877-880.

40. Wilkins R, Bisson $\sqcup$ (2012) Operative versus nonoperative management of acute Achilles tendon ruptures: a quantitative systematic review of randomized controlled trials. Am J Sports Med, 40: 2154-2160.

41. Willits K, Amendola A, Bryant D, Mohtadi NG, Giffin JR, Fowler P, Kean CO, Kirkley A (2010) Operative versus nonoperative treatment of acute Achilles tendon ruptures: a multicenter randomized trial using accelerated functional rehabilitation. J Bone Joint Surg Am, 92: 2767-2775.

42. Wong J, Barrass V, Maffulli N (2002) Quantitative review of operative and nonoperative management of Achilles tendon ruptures. Am J Sports Med, 30: 565-575. 